\title{
JOB CRAFTING: TOWARDS A NEW MODEL OF INDIVIDUAL JOB REDESIGN
}

\section{Authors:}

Maria Tims

Arnold B. Bakker

\section{Affiliations:}

${ }^{1}$ Erasmus University

Rotterdam, Institute of

Psychology, Department of

Work and Organizational

Psychology, Rotterdam,

The Netherlands

\section{Correspondence to:}

Maria Tims

email:

tims@fsw.eur.nl.

\section{Postal address:}

Erasmus University

Rotterdam, Department of

Work and Organizational

Psychology, Woudestein,

T12-59, PO Box 1738,

3000 DR Rotterdam, The

Netherlands

\section{Keywords:}

employee engagement; individual job redesign; JD-R model; job crafting; positive organisational behaviour

\section{Dates:}

Received: 10 July 2009

Accepted: 11 Sept. 2009

Published: 03 Dec. 2010

How to cite this article:

Tims, M., \& Bakker,

A.B. (2010). Job crafting:

Towards a new model of individual job redesign.

SA Journal of Industrial

Psychology/SA Tydskrif vir

Bedryfsielkunde, 36(2), Art.

\#841, 9 pages. DOI: 10.4102/ sajip.v36i2.841

This article is available at:

http://www.sajip.co.za

(c) 2010. The Authors.

Licensee: OpenJournals

Publishing. This work

is licensed under the

Creative Commons

Attribution License.

\section{ABSTRACT}

Orientation: For a long time, employees have been viewed as passive performers of their assigned job tasks. Recently, several scholars have argued that job design theory needs to address the influence of employees on their job designs.

Research purpose: The purpose of the study was to fit job crafting in job design theory.

Motivation for the study: The study was an attempt to shed more light on the types of proactive behaviours of individual employees at work. Moreover, we explored the concept of job crafting and its antecedents and consequences.

Research design, approach and method: A literature study was conducted in which the focus was first on proactive behaviour of the employee and then on job crafting.

Main findings: Job crafting can be seen as a specific form of proactive behaviour in which the employee initiates changes in the level of job demands and job resources. Job crafting may be facilitated by job and individual characteristics and may enable employees to fit their jobs to their personal knowledge, skills and abilities on the one hand and to their preferences and needs on the other hand.

Practical/managerial implications: Job crafting may be a good way for employees to improve their work motivation and other positive work outcomes. Employees could be encouraged to exert more influence on their job characteristics.

Contribution/value-add: This article describes a relatively new perspective on active job redesign by the individual, called job crafting, which has important implications for job design theories.

\section{INTRODUCTION}

Job design continues to be of great practical significance to organisations. A well-designed job may lead to increased employee well-being and may set the stage for thriving, that is, when individuals surpass challenges at work and personally grow from them (Strümpfer, 2006). Job design describes how 'jobs, tasks, and roles are structured, enacted and modified and what the impact of these structures, enactments and modifications are on the individual, group, and organizational outcomes' (Grant \& Parker, 2009, p. 5). Job design is usually seen as a top-down process in which the organisation creates jobs and in turn selects people with the right knowledge, skills and abilities for the jobs. Job redesign is usually seen as a process in which the supervisor decides to change something in the job, tasks or roles of the individual. However, there is an alternative, new perspective on job redesign, namely job redesign on the individual level. Accordingly, employees are hired by the organisation first and then the employees start to change the job in such a way that it better fits their abilities and preferences. In other words, employees start to customise their jobs to their individual needs and preferences (Berg, Dutton \& Wrzesniewski, 2008) instead of reactively performing the job that the organisation created. In this view, employees are seen as also being responsible for their work outcomes. This is an important switch in job redesign theory.

At first, the changes that employees make in their job design were thought to take place during the process of socialisation (Schein, 1971), but it has become evident that it also happens when people have been working in the same organisation for a long time. Thus, employees adapt to changes in the work situation and change aspects of their work environment themselves.

The aims of the present article are twofold. Firstly, we will review job redesign theory from the individual level and explore the active role that employees take in redesigning their own jobs. The literature about job redesign already provides examples of employees taking a proactive stance, for instance in changing certain work procedures that are faulty or proposing innovative solutions to problems at work. Most of these behaviours are highly valuable to the organisation because they enhance the chance of survival in changing work environments (Staw \& Boettger, 1990).

However, we feel it is important to also focus on the changes that employees make in their jobs to enhance or benefit their own goals (such as a better person-job fit, more enjoyable work, better well-being, less work-home conflict, etc.). Strümpfer (1990) also argues that employees who are resilient (i.e. possess a high sense of coherence, personality hardiness and an internal locus of control) develop 'occupational self-direction'; that is, they use initiative, thought and independent judgement in their work. This may help them to remain healthy and to be able to deal with stressors as challenges instead of high pressures.

Secondly, we will explore the concept of job crafting in more detail and frame it using the job demandsresources model (Bakker \& Demerouti, 2007) in order to enhance clarity about the concept of job crafting and to help researchers investigating it. We feel that job crafting as it is defined at this moment may be 
a bit general, while we are interested in the actual behaviours of individual employees who redesign their jobs. We therefore propose a theoretical model that can be used to study the jobcrafting behaviours of individuals and that can be applied by organisations to stimulate individual-level job redesign. This model also includes specific work characteristics and individual differences that may explain why some people are more likely to be job crafters than others.

We will turn to the discussion of the literature about active job redesign by the employee now and then focus on job crafting in more detail.

\section{Early approaches to individual-level changes at work}

We will focus on the proactive behaviours of individuals at work in shaping and customising their job tasks, work settings and employment conditions (Hornung, Rousseau \& Glaser, 2008; Wrzesniewski \& Dutton, 2001). These behaviours are embedded in role theory, which states that employees with the same jobs will perform a slightly different set of tasks because they enact their roles in different ways (cf. Biddle, 1979).

\section{Role innovation}

In the case of role innovation, an employee proactively redefines the entire work role by changing the mission or practice of the role (Van Maanen \& Schein, 1979). Role innovation is said to be triggered when the role as it is currently shaped is not able to address the problems that are faced (Schein, 1971). Thus, when employees notice a problem in the definition of the work role, they try to redefine the role in an innovative way. Role innovation can be enhanced when socialisation processes reinforce the individual to engage in it. For example, the exposure to innovative role models and an individual socialisation process may encourage the new employee to change the organisationally defined role. As a result, the profession concerned becomes more capable of handling new or future situations and has a greater chance of survival.

\section{Task revision}

Another possibility is that work roles are misspecified. When work roles are misspecified or when work practices are erroneous, counter-role behaviour can be of value to the organisation. Task revision is seen as a form of counterrole behaviour in that it is about resistance to certain faulty procedures at work, to inaccurate job descriptions, or to a dysfunctional role expectation (Staw \& Boettger, 1990). However, from the experiments reported on by Staw and Boettger (1990) in their article, it appears that task revision rarely occurs in work settings. The reason for this may be that counter-role behaviours such as resistance to social norms and expectations are regarded as being unvalued by the organisation and, therefore, not appropriate in the eyes of managers and employees. Thus, an employee must really see the value of acting against the norms before they will direct effort into making corrections to tasks. A work environment that is supportive of deviation and peers who are like-minded could facilitate the occurrence of task revision (Staw \& Boettger, 1990).

\section{Voice}

Voice is defined as 'nonrequired behavior that emphasizes expression of constructive change with the intent to improve rather than merely criticize' (LePine \& Van Dyne, 1998, p. 109). It therefore requires proactivity from the employee and also willingness to be non-conformist. It may take forms such as suggesting more effective ways of doing things in the organisation. As LePine and Van Dyne (1998) write when discussing practical implications, knowledge about voice is especially important to managers in dynamic organisations, in which change and innovative ideas are essential for the organisation to survive. Thus, the organisation has a lot to gain when individuals express voice, although it does not necessarily benefit the individual. Of course, valuable changes may also lead to a better performance appraisal.

All concepts mentioned above are of great value to organisations. When people stand up and express innovative and better ideas regarding performance, the organisation as a whole may benefit from these new perspectives. This will enhance the survival of the organisation, especially in a changing environment. Although these behaviours capture the initiative and activity of the employee in bringing about change at work, they are not focused especially on benefits for the individual. We now turn to proactive behaviours that are more focused on enhancing benefits for the individual worker.

\section{Idiosyncratic deals}

Some individuals negotiate individualised arrangements for work with their employer - the most common are more flexible work hours and more opportunities for development. These individual work arrangements between an employee and an employer are called idiosyncratic deals or, in short, i-deals (Hornung et al., 2008; Lai, Rousseau \& Chang, 2009). I-deals are intended to benefit both the employee and the organisation. These deals usually arise because the employer finds the employee to be valuable to the organisation and, by granting him/her more flexibility, for example, helps the organisation to retain this employee. Both the organisation and the employee win in this situation. I-deals are a good solution for a better work-life balance and for more opportunities for personal development. However, the pitfall with i-deals is that other employees in the organisation might perceive the i-deal to be fair and to be applicable to them in the future as well (Lai et al., 2009). When colleagues of an 'i-dealer' believe the i-deal is not available to them in the future, they may feel that the employer is favouring that employee, causing their trust in and respect for the organisation to be undermined. Negotiating an i-deal is seen as a form of proactive behaviour because it requires employees to inform their employer of their needs and to negotiate the fulfilment of these needs (Hornung et al., 2008).

\section{Personal initiative}

The last concept to be addressed here is personal initiative. Personal initiative is defined as self-starting behaviour by the employee that is consistent with the mission of the organisation, has a long-term focus, is goal directed and action oriented and is persistent in the face of difficulties (Frese, Fay, Hilburger, Leng \& Tag, 1997). It is important to note that these actions go beyond what is required from the individual at work. Personal initiative is triggered by the work environment and therefore mainly directed toward work and organizational issues (Frese, Garst, \& Fay, 2007).

Role innovation, task revision, voice, i-deals and personal initiative are called active performance concepts because they imply that people can go beyond their assigned tasks to develop their own goals and adopt a long-term perspective to prevent problems (Parker, Williams \& Turner, 2006). Furthermore, these proactive changes that employees make in their job design are usually focused on resolving problems for the organisation (LePine \& Van Dyne, 1998) and thus do not specifically contribute to individual outcomes, such as better health, wellbeing or work engagement. It may be argued that, in the end, the employee may profit from the positive outcomes they bring about in the organisation, although the focus of these concepts is not necessarily on these individual outcomes.

We will now turn to the active changes that employees may make in the design of their jobs in order to enhance benefits for the individual. Employees may actively change the design of their jobs by choosing tasks, negotiating different job 
content and assigning meaning to their tasks or jobs (Parker \& Ohly, 2008). Job crafting has recently been posited as a way of individually redesigning the job in order to enhance personal (work) outcomes in the first place (Wrzesniewski \& Dutton, 2001). However, we will propose indirect benefits for the organisation as well in the Discussion section.

\section{Job crafting}

Job crafting differs from the former concepts in that it is about proactive changes in the job design that are not specific arrangements that are negotiated with the organisation (supervisor). It is suggested that these changes are probably not even noticed by the manager (Wrzesniewski \& Dutton, 2001). Also, the definition of job crafting does not explicitly state a longer time focus. Job crafting may also occur as a solution of short duration in a demanding period. This is thought to happen often, not only as a means of solving problems. As a final difference, job crafting is not necessarily in line with the goals of the organisation.

Job crafting is defined as changing the boundaries and conditions of job tasks and job relationships and of the meaning of the job (Wrzesniewski \& Dutton, 2001). Thus, employees can change how work is conceptualised and carried out (i.e. changing task boundaries), how often and with whom they interact at work (i.e., changing relationship boundaries) and how they cognitively ascribe meaning and significance to their work (i.e. changing meaning). Job-crafting behaviours may lead to many positive outcomes, such as work engagement, job satisfaction, resilience and thriving (Berg et al., 2008). Thus, job crafting is seen as a very promising concept in organisational psychology, although it has not received much research attention.

Job crafting is investigated mostly through qualitative research and research on specific work domains. A study by Lyons (2008) demonstrated that job crafting does take place at work and usually without the knowledge of supervisors. Lyons used an interview study to investigate how often job crafting occured and found that $78 \%$ of the sample $(N=105)$ reported a minimum of one job-crafting attempt and that a considerable number of these job-crafting behaviours were directed toward tasks and relationships at work. Ghitulescu (2006) examined the predictors (i.e. skills, task complexity and task discretion) and outcomes (i.e. job satisfaction, organisational commitment, job effectiveness and absenteeism) of task, relational and cognitive job crafting in a manufacturing context where 164 workers reported their job crafting behaviours (except for task crafting which was rated by the supervisor) and supervisors reported the effectiveness of the employees (i.e. efficiency and quality). The results of this study showed that the skills of the employees significantly predicted task crafting, task complexity predicted cognitive crafting and that task discretion and task complexity both predicted relational crafting.

In addition, the outcomes of the job crafting behaviours in Ghitulescu's (2006) study were as follows: Task crafting and one dimension of relational crafting (i.e. strength of interaction) had a positive effect on efficiency of work and output quality, whereas range of interaction with others (i.e. second dimension of relational crafting) had a significant negative effect on quality. Cognitive crafting related significantly to both the affective outcomes of job satisfaction and commitment, whereas task crafting only predicted commitment. Relational crafting predicted none of these affective outcomes. These results indicate that the three dimensions of job crafting are predicted (partly) by different antecedents and that they themselves predict (partly) different outcomes.

We wish to illustrate here that researchers used different measurement instruments for assessing the three aspects of job crafting. For example, Ghitulescu (2006) had supervisors rating the initiative of subordinates on their tasks to see how employees crafted their tasks at work. However, as stated above, job crafting usually takes place without the supervisor even knowing about it. Relational crafting was measured with a question asking how often the employee was in contact with others at the job (these interactions were not part of the formal job duties). Cognitive crafting was measured with the task significance measure of Hackman and Oldham (1976). These measures do not explicitly inform us of what it is that employees craft, since asking how often people meet others does not tell us whether employees actually changed the number of interactions with others at work. Other job crafting measures were tailored to the specific profession of the participants and therefore are not suited for general use (cf. Ghitulescu, 2006, Study 2).

In short, there is no consensus yet on how to examine job crafting empirically and generally. We wish to address this gap in the literature by proposing a job demands-resources (JD-R) perspective in job crafting research. The JD-R model divides all work characteristics into job demands and job resources and therefore seems appropriate to use for investigating what specific aspects employees change in their job design.

\section{The job demands-resources model}

The JD-R model (Bakker \& Demerouti, 2007; Demerouti, Bakker, Nachreiner \& Schaufeli, 2001) assumes that every work environment has its own unique characteristics that can still be captured in one overall model. Therefore, it is more flexible and rigorous than previous job design models, such as the job characteristics model (Hackman \& Oldham, 1976) and the demand-control model (Karasek \& Theorell, 1990). More specifically, the JD-R model is a heuristic model that specifies how employee well-being and effectiveness may be produced by two specific sets of working conditions. The first set of working conditions concerns job demands, which represent characteristics of the job that will potentially evoke strain if they exceed the employee's adaptive capability (Bakker, Hakanen, Demerouti \& Xanthopoulou, 2007). The JD-R model applies a broader view of job demands when compared to Karasek's demands, which are mainly quantitative in nature, such as workload and time pressure (Bakker, Demerouti \& Schaufeli, 2003). More specifically, job demands refer to those physical, social or organisational aspects of the job that require sustained physical or mental effort and are therefore associated with certain physiological and psychological costs (Demerouti et al., 2001). Examples are high work pressure and emotionally demanding interactions with clients. The second set of working conditions concerns the extent to which the job offers resources to individual employees (Bakker et al., 2007). Job resources refer to those physical, psychological, social or organisational aspects of the job that, (1) may be functional in achieving work goals, (2) may reduce job demands and the associated physiological and psychological costs and (3) may stimulate personal growth and development. Job resources are the main initiators of employees' work engagement and consequently of enhanced performance (Xanthopoulou, Bakker, Demerouti \& Schaufeli, 2009). Job resources may be located at the organisational level (e.g. pay, job security, career opportunities), at the interpersonal level and that of social interactions (e.g. supervisor and coworker support, team climate), at the level of organisation of work (e.g. role clarity, participation in decision making) and at the level of the task (e.g. skill variety, task identity, task significance, autonomy, performance feedback). Job resources have both intrinsic and extrinsic motivational potential (Bakker \& Demerouti, 2007). They are intrinsically motivating because they fulfil basic human needs and foster individuals' growth and development (Deci \& Ryan, 2000; Van den Broeck, Vansteenkiste, De Witte \& Lens, 2008). As extrinsic motivators they may be instrumental in achieving work goals.

There are two different underlying psychological processes that play a role in the development of job strain and work 
motivation. The first is labelled the health impairment process, by which poorly designed jobs or chronic job demands exhaus employees' mental and physical resources and therefore may lead to the depletion of energy and to health problems (Bakker \& Demerouti, 2007; Demerouti et al., 2001). Here, burnout mediates the relationship between job demands (and to a lesser extent poor resources) on the one hand and negative (health) outcomes on the other hand. This health impairment process is supported by research in which occupational stress resulting from high job demands is related with ill physical and psychological health (Jackson \& Rothmann, 2006), repetitive strain injury (Bakker et al., 2003) and sickness absenteeism (Peterson, Demerouti, Bergström, Ásberg \& Nygren, 2008; Rugulies et al., 2007)

The second process proposed by the JD-R model is a motivational process, in which it is assumed that job resources have motivating potential and lead to high levels of work engagement, low cynicism and excellent performance. Thus, work engagement (i.e. characterised by high levels of vigour, dedication and absorption) mediates the relationship between job resources and positive outcomes, such as commitment to the organisation (Bakker \& Schaufeli, 2008; Hakanen, Bakker \& Demerouti, 2005; Richardsen, Burke \& Martinussen, 2006), extra-role behaviour (Bakker, Demerouti \& Verbeke, 2004), connectedness with the organisation (Lewig, Xanthopoulou, Bakker, Dollard \& Metzer, 2007) and client satisfaction (Salanova, Agut \& Peiró, 2005).

In addition to the main effects of job demands and resources, the model proposes that the interaction between job demands and job resources is also important for the development of job strain and motivation. Job resources may buffer the impact of job demands on job strain, including burnout (Bakker, Demerouti \& Euwema, 2005; Xanthopoulou et al., 2007). In addition, job resources are most strongly related to engagement when the employee experiences high job demands. Several studies have provided evidence for this interaction effect (see Bakker et al., 2007; Hakanen et al., 2005).

\section{Job crafting framed in the JD-R model}

In order to use the JD-R model to guide job crafting research, we frame job crafting in terms of this model. More specifically, we feel that employees may change their levels of job demands and job resources in order to align them with their own abilities and preferences. An employee may craft these aspects of the job in three ways according to this model:

- The employee may increase the level of job resources available at work.

- The employee may increase the level of job demands at work.

- The employee may decrease the level of job demands at work.

The second and third dimensions might seem contradictory, but, as LePine, Podsakoff and LePine (2005) point out, some demands can be hindering and therefore stressful (e.g working with the wrong materials), while other demands can be challenging for the employee (e.g. high task complexity) We decided to take both into account, because decreasing the hindrance demands and increasing the challenge demands may both lead to positive outcomes for the employee (e.g. enhanced well-being and thriving). We will explain the three dimensions in more detail now.

\section{Increasing the level of job resources}

Job resources are very important predictors of positive work outcomes, such as work engagement, commitment and client satisfaction, but also act as a buffer to undesired work outcomes, such as burnout (Bakker et al., 2005). Thus, in general it would be valuable to have a high level of job resources at work. However, in some work situations the level of job resources may be low, for example when there are no colleagues available for social support or when employees have no autonomy. In this situation it may be good for the employee if he or she could mobilise more job resources in order to be able to deal with the job demands without too much difficulty.

Mobilising job resources is in line with conservation of resources (COR) theory (Hobfoll, 1989), which states that successfully dealing with high job demands is only possible if one has the resources that are helpful in dealing with these demands. It follows then that employees who have more resources will experience less stress than employees who have fewer resources (Salanova, Schaufeli, Xanthopoulou \& Bakker, 2010). Furthermore, employees who invest resources are likely to gain other resources. Research suggests that employees who are able to mobilise their job resources experience more work engagement and, in turn, this may lead to more resource gains. For example, Salanova, Bakker and Llorens (2006) found that work-related flow of teachers (i.e. absorption, work enjoyment and intrinsic work motivation) at the end of the school year was predicted by their level of job resources at the beginning of the school year and also the reverse, namely that flow at the beginning of the school year positively predicted resources at the end of the year. Note that we do not expect employees to lower their amount of job resources, seeing that job resources are positively related to favourable work outcomes.

\section{Increasing the level of job demands}

The second form of job crafting may be that employees create a higher level of job demands at their work. In other words, they may create more challenges at their work when they feel that their job is not offering them enough opportunities to use all their skills. Employees may increase their level of job demands by adding tasks to their jobs, volunteering for interesting project groups, or taking over tasks from their supervisor.

These demands are called challenge demands (LePine et al. 2005). Challenge demands are not depleting one's energy and are not related to negative work outcomes such as job dissatisfaction and ill health. Instead they are related to goal attainment and work motivation (Cavanaugh, Boswell, Roehling \& Boudreau, 2000). This implies that not all demands are bad for employees, since some demands may result in increased efforts by the employee, which in turn may lead to satisfaction when attaining a difficult goal. In their study, Cavanaugh and colleagues showed that self-reported job demands were related to either positive (i.e. job satisfaction, less job search and less voluntary turnover) or negative (job dissatisfaction, job search and voluntary turnover) work outcomes, depending on the demand that was investigated. All challenge demands (i.e. high workload, time pressure, job scope and high responsibilities) produced positive work outcomes.

It is expected that employees only increase their level of job demands when they have enough job resources available to deal with them. In other words, adding job demands while there are not enough job resources to handle them will increase the likelihood of health impairment; in this case employees have to invest too much effort.

\section{Decreasing the level of job demands}

The third form of job crafting that employees may employ is by decreasing the level of job demands when these exceed their capabilities. They may do so by asking colleagues to help them with their tasks, or by reducing the number of interactions they have with demanding customers or colleagues. In this way, the employee may be able to attain the work goals without too much effort and by staying healthy. Building on the notion of challenge demands, these demands are called hindrance demands because they hinder the employee in achieving valued goals (Cavanaugh et al., 2000). Examples are role ambiguity, concerns about job security and role conflict (LePine et al., 2005). For employees it is thus important to find a way to lower the levels of hindrance demands in order to perform well and to be satisfied with their jobs.

The attentive reader may notice now that we did not include the cognitive dimension proposed by Wrzesniewski and Dutton 
(2001) (i.e. changing the meaning of work). We feel that cognitive change may be more like coping with the circumstances as they are and not about actively shaping the boundaries of one's work, which is the definition of job crafting as proposed by Wrzesniewski and Dutton. Our aim is to research the actual behaviour of employees in modifying their job design to enhance their own work motivation. The other two dimensions defined by the aforementioned authors (i.e. changing the task and relational boundaries of one's work) are in line with the dimensions we proposed. For example, changing the relational boundaries can be found in our dimension of mobilising job resources, since social support and other relationships can be seen as job resources.

The focus in the remainder of this article is on work characteristics and individual differences that may explain why some people are better job crafters than others.

\section{Antecedents of job crafting}

In this section we report characteristics of the work situation and characteristics of employees that may be moderators of job-crafting behaviours. We will start with the characteristics of the work situation, since they may play an important role in facilitating job-crafting behaviours. Then we will discuss individual characteristics of people that may explain why some persons are more likely to craft their job than another person. The included work characteristics and individual differences that are discussed here are necessarily selective rather than exhaustive and the whole model is summarised in Figure 1.

\section{Person-job fit}

As a result of the aforementioned level of job demands and job resources that are inherent in the employees' jobs, there may either be a person-job fit or a person-job misfit. There are two aspects of person-job fit, namely, (1) the fit between an individual's knowledge, skills and abilities on the one hand and the job demands on the other hand (i.e. demands-abilities fit; Cable \& Judge, 1996; Lauver \& Kristof-Brown, 2001) and (2) the fit between the needs and desires of an individual and what is provided by the job (i.e. needs-supplies fit; Cable \& DeRue,
2002). Thus, person-job fit incorporates what a worker can do and wishes for in the job and what the job demands from and offers the worker. When these factors are in balance, the employee is likely to experience a good fit to the job, but there may also be a misfit when one (or both) of the aspects are not balanced.

For example, a job that requires a thorough knowledge of computer processes but does not offer a less skilled worker opportunities to follow courses, may lead to misfit being experienced by this employee (i.e. demands-abilities misfit). If one is able to solve this misfit by learning from more experienced colleagues, the fit can be restored. Job crafting may be a good way to accomplish this, because the employee knows what causes the misfit and how to reduce it. The existence of a misfit is then a trigger to engage in job crafting. This view is not entirely new: Frese and Fay (2001) argued that negativity at work, such as job dissatisfaction (e.g. following a misfit), is often the reason for employees to engage in proactive behaviour.

Proposition 1: Person-job misfit leads to job-crafting behaviours

\section{Autonomy}

The characteristics of the work environment may themselves play an important role in enhancing the possibility to make changes in the job design. Autonomy at work is an important work characteristic and is defined as the extent to which a job allows one the freedom to schedule work, make decisions and select the methods used to perform tasks (Hackman \& Oldham, 1976). Autonomy at work is often essential for employee health, because a high level of discretion at work is associated with more opportunities to cope with stressful work situations (Bakker et al., 2005). When autonomy is enhanced, employees also report acquiring new skills and experiencing more responsibility for problems at work (Parker, 1998). The opportunity to decide for oneself what and how to do the job may therefore be a precondition for job crafting (Wrzesniewski \& Dutton, 2001)

If employees feel they have no freedom/opportunity to craft their jobs they are less likely to attempt to change some aspects of their jobs. Thus, an important condition will be that

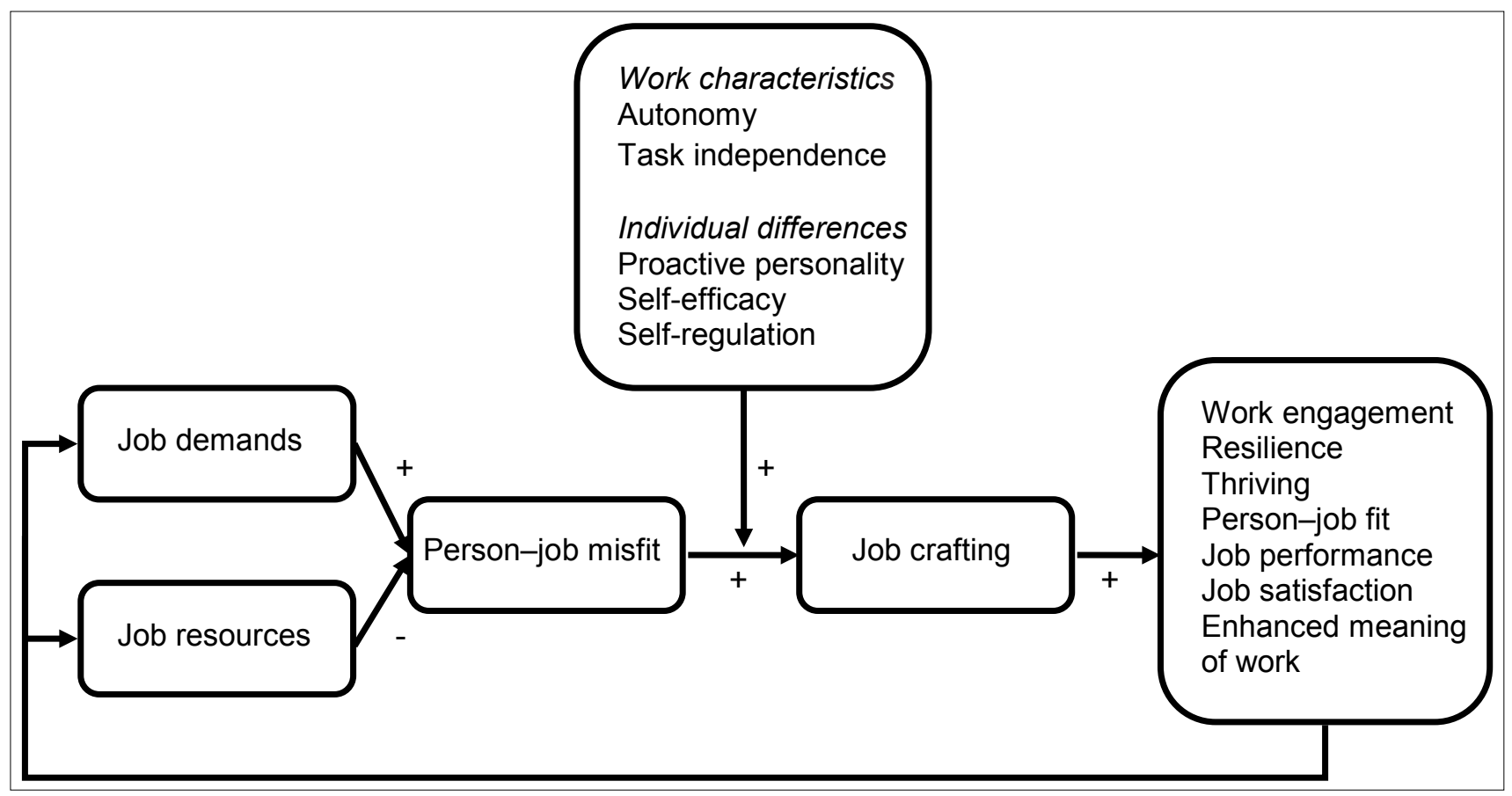

FIGURE 1

Proposed model of job crafting 
employees have enough control over their work to perceive that they have the opportunity to enact their ideas or wishes. In the research conducted by Lyons (2008), perceived control was measured as a facilitating aspect of work that would enhance the job-crafting behaviours of salesmen. Less than a quarter of the sample $(23 \%)$ reported to perceive many opportunities to make changes in their work, while $39 \%$ said they had no or very little opportunity to make changes. This is a very surprising finding for a sales job, in which people are thought to have substantial freedom over their behaviours and it needs to be addressed in future research.

\section{Task independence}

Job crafting is more likely to occur when employees perform tasks that can be performed independently of each other When employees do not have to rely on the performance of other colleagues it will be easier to make some adjustments to the job to facilitate positive outcomes. In contrast, when employees perform tasks that are highly interdependent (i.e. where successful performance is dependent on the successful performance of others; Kiggundu, 1983), it may be very difficult to proactively change something in the job. Such a change would imply that it also changes something for the other employees who are dependent on the performance of the job crafter (Wrzesniewski \& Dutton, 2001). Since job crafting is thought to take place to enhance individual benefits, it is likely that the dependent others are not always positively affected by these changes.

Proposition 2: High levels of autonomy and task independence facilitate job crafting because employees will experience the freedom to make changes in their jobs.

\section{Individual differences}

We now turn to the individual differences that may play a role in job crafting.

\section{Proactive personality}

An important moderator of proactive behaviours (such as job crafting) is a proactive personality (Crant, 2000). People with a proactive personality are expected to engage in job crafting more readily than people without this characteristic, since they take the initiative in improving current circumstances, identify opportunities for change, take action and persevere until they bring about meaningful change (Bateman \& Crant, 1993; Crant, 1995; 2000; Grant \& Ashford, 2008). It is assumed that proactive individuals create their own environment and therefore are more likely to be effective in their jobs (Crant, 1995; 2000). Thus, proactive employees are more likely to change those aspects of their jobs that are not contributing to the attainment of certain work goals. For example, they anticipate future demands and take action to overcome or prevent these demands (Fay \& Frese, 2001). It is therefore expected that these individuals will also be able to craft their jobs in such a way that they themselves experience more positive outcomes in their jobs. Research already suggests that proactive persons show more innovative behaviour at work, which is a form of active involvement in change at work (Seibert, Kraimer \& Crant, 2001).

\section{Self-efficacy}

The belief employees have in their abilities to engage in certain tasks or to make changes in the work environment will most likely influence employees' job-crafting behaviours. Employees who feel self-efficacious are more likely to act (Vough \& Parker, 2008). Thus, employees with a high level of self-efficacy feel that they have a high likelihood of success in performing the behaviour. There is evidence that self-efficacy is related to proactive concepts such as taking charge (Morrison \& Phelps, 1999) and personal initiative (Speier \& Frese, 1997). Moreover, when employees have experienced positive outcomes from earlier attempts to craft different tasks, for instance, they might also be more likely to engage in job redesign at a later time ( $c f$. Bandura, 1977). Salanova et al. (2010) refer to a Spanish study by Ventura, Salanova and Llorens (2008) showing that high levels of self-efficacy related to high levels of challenge demands and that these, in turn, positively predicted work engagement. This suggests that high efficacy beliefs may lead to the crafting of challenging job demands, while low levels of self-efficacy may not lead to job crafting.

\section{Regulatory focus}

A third individual-difference variable that may be highly relevant for crafting behaviour is regulatory focus. Regulatory focus theory proposes that individuals can have a promotion focus (i.e. ideal self-regulation) or a prevention focus (i.e. ought self-regulation). The former is concerned with advancement, growth and accomplishment, whereas the latter is concerned with security, safety and responsibility (Crowe \& Higgins, 1997). Individuals high in promotion focus are sensitive to positive outcomes and thus approach situations with an expected positive outcome (Higgins, 1998). Accordingly, they may be more likely to change aspects of the job in order to be more satisfied and effective than individuals with a prevention focus. It is assumed that those employees who strive for advancement and growth may accomplish that by crafting their jobs.

Proposition 3: High levels of proactive personality, selfefficacy and focus on promotion lead employees to engage more readily in job crafting than individuals who score low on these individual-difference variables.

\section{Stimulating job crafting through tailored feedback}

The general view held in this article is that job crafting is a good means to enhance person-job fit and, as a consequence, many other positive outcomes for the employee and in the end also for the organisation. However, we also acknowledge that not all employees are likely to engage in job crafting when their job demands or resources are not balanced. We have already mentioned that individual differences, such as proactive personality and the level of self-efficacy, may influence who is more likely to react to certain work situations through job crafting. However, it is important to also think about the employees who are less likely to craft their jobs because they may also benefit from it. For example, employees who are at risk of burnout because of a very high workload may experience a better work situation when their workload is decreased or when their level of job resources are increased and in the end they will hopefully remain healthy. In other words, these less proactive individuals need to be stimulated or encouraged to change certain tasks or aspects of their jobs.

We propose that this might be accomplished through providing employees with web-based tailored feedback on their work situation. Organisations can use an internet application of the JD-R model, through which employees who complete an online JD-R questionnaire receive online, tailored feedback on their most important personal job demands and job resources (Bakker et al., 2005). Tailoring is a technique in which information is fit to the individual (Smeets, Kremers, De Vries \& Brug, 2007). It includes less redundant information than a general approach and is therefore more likely to be read, stored in memory, remembered and used (Skinner, Campbell, Rimer, Curry \& Prochaska, 1999). In addition, it seems to be more effective in behaviour change. A meta-analysis of 57 studies suggested that tailored messages were better in affecting changes in health behaviour (Noar, Benac \& Harris, 2007), which supports the conclusion of the review mentioned above (Skinner et al., 1999). Tailored feedback also has better longer term effects on changes in behaviour than non-tailored feedback interventions (Vandelanotte, De Bourdeaudhuij \& Brug, 2007).

These results show that, when feedback is tailored to the individual, he or she is more likely to act. With the model of job crafting developed in this article, we feel it may be easier for employees to engage in job crafting when their levels 
of job demands and job resources are evaluated and they receive tailored feedback about their person-job (mis)fit (i.e. demands-abilities and needs-supplies fit). A possible method to achieve this would be to first assess how the job demands are experienced by the employee and how many demands this person is able to handle according to their level of skills and knowledge. This analysis would indicate whether there is a discrepancy between the abilities of the person and the actual demands on their and thus whether there is a need to craft certain tasks. Secondly, the resources a person has for doing the job should be assessed, as well as the job resources he or she needs in order to perform well. This analysis will indicate whether there is a needs-supplies fit and what job resources would be the best candidates for crafting. If there appears to be no misfit between the job demands and resources in the environment and the employee's abilities and needs, then there is also no explicit reason to redesign the job. However, as was pointed out earlier, there may be a need to enhance the challenges at work. Feedback would then be provided to the employee. In sum, we propose that employees who receive tailored feedback about their current levels of job demands and resources are more likely to act and change their jobs accordingly because they pay more attention to the personalised feedback.

Proposition 4: Job crafting may be stimulated with tailored feedback because employees find it personally relevant and are therefore more likely to use the feedback to guide their actions.

\section{Consequences of job crafting}

Job crafting may lead to many positive outcomes for the employee as well as for the organisation. We have already mentioned a few of these outcomes throughout the article. Firstly, as Wrzesniewski and Dutton (2001) proposed, job crafting may lead to enhanced meaning of work and a positive work identity. By making changes in the job it will be possible to experience the job in another way and to craft another purpose of the work. Secondly, we propose that job crafting may enhance person-job fit and that this, in turn, may lead to high levels of job satisfaction and positive organisational outcomes, such as organisational commitment and employee retention (KristofBrown, Zimmerman \& Johnson, 2005). People who are active in shaping their environment are also more likely to experience better well-being because they might feel that they have more control over their environment.

Proposition 5: Job crafting leads to positive outcomes for the employee (e.g. person-job fit, enhanced meaning, job satisfaction, work engagement) as well as for the organisation (e.g. commitment, high performance, reduced personnel turnover)

We furthermore suggest there may be a feedback loop between these positive outcomes and the level of job demands and resources. When employees experience positive emotions, it might be possible that a so-called gain spiral develops from positive outcomes to the level of job resources and demands. For example, research by Salanova et al. (2006) showed that job resources predicted work-related flow (a concept close to work engagement, including absorption, enjoyment and intrinsic motivation) and that this positively influenced job resources. It is therefore expected that motivated and healthy employees influence their levels of job demands and job resources over time in such a way that they accumulate resources and challenging demands and/or lower the amount of hindrance demands. This leads us to formulate the last proposition:

Proposition 6: There is a feedback loop from positive outcomes to levels of job demands and resources, such that positive outcomes have a positive effect on the level of job resources and challenge demands and a negative effect on hindrance demands.

\section{DISCUSSION}

In this article we focused on the active role of employees in determining their job demands and job resources. We briefly reviewed the literature on proactivity at work by first describing the changes made by employees that mostly benefitted the survival of their organisation and then discussed concepts that were more important for benefits at the individual level. Job crafting is seen as a very valuable means for individuals to customise their jobs to their own abilities, preferences and wishes. We also recognised that there may be moderating work characteristics (e.g. autonomy and task independence) and individual differences (e.g. proactive personality, selfefficacy, regulatory focus) that may stimulate some employees to craft their jobs more than other employees. Tailored feedback is proposed as a means to stimulate all employees to engage in job crafting. This type of feedback is assumed to have a positive effect on the elaboration of the message and therefore the feedback will be retained better and is more likely to affect the attitude and behaviour of the employee (Petty \& Cacioppo, 1986).

Allowing employees to engage in job crafting may be a valuable means for organisations to keep their workers motivated by acknowledging that each employee is different and should be allowed to shape their job accordingly (within certain borders). Although we feel that job crafting is a good remedy for employees to enhance their work motivation and well-being, there are some limitations, which are discussed below.

\section{Limitations of the study}

Firstly, because of the individual focus of job crafting it may be hard to detect what the immediate impact of job crafting is on the organisation. There may be situations in which it is possible that the changes an employee makes in their job design may lead to unwanted effects for the organisation. For example, a service worker may decide to work fewer hours behind the service desk in order to reduce the emotional demands imposed on him by customers. This may lead to fewer emotional demands for the respective employee, but it may reduce customer satisfaction because the clients need to wait longer for the service. However, we do believe that job-crafting behaviours will contribute to better outcomes for the organization most of the time, since happy and healthy employees are more likely to contribute positively to the organisation.

Secondly, the role of the supervisor may be a bit too simplistic. We assume that employees engage in job crafting without awareness of their supervisors. This may be true in some situations (e.g. crafting more social support from co-workers), but not in all cases. In some instances the supervisor may be needed to help employees by allocating them time to follow a course, for example. Furthermore, the supervisor plays an important role in providing feedback to the employee about work behaviours and may therefore also stimulate job-crafting behaviours. Supervisors can also build employees' self-efficacy by providing them the opportunity to experience mastery/ success at work (Bandura, 2001). More research attention therefore needs to be paid to the role and influence of the supervisor on job crafting.

Thirdly, the question of how to stimulate employees to actively change aspects of their work that are causing them stress (because they are too demanding or boring) is hard to answer. We proposed that offering employees tailored feedback about their current level of job demands and resources in relation to their abilities and needs may make them aware of the potential 'problem areas'. In addition, they may be offered suggestions about how they can address these misfits. It is difficult to state how often this feedback should take place. It might be advisable to monitor the levels of job demands and job resources once a year and then to evaluate them again after three or six months in 
order to investigate whether the employees were able to adjust them according to the feedback. However, a time frame that is too short will not reveal any of the changes that may take more time to accomplish, whereas some job-crafting behaviours may be relatively short in duration and will not be captured after a longer time.

\section{Recommendations for future research}

There is still a lot of knowledge to be gained through jobcrafting research. Firstly, research may test the propositions formulated in this article or the proposed model as a whole. Secondly, longitudinal studies should aim to address the long-term consequences of job crafting. Do employees who redesigned certain aspects of their tasks really feel better and more motivated than individuals who complied with their assigned tasks? A related question that is highly relevant for organisations is whether these employees are also more productive and absent less often. Thirdly, it needs to be tested whether a feedback intervention is a proper means to stimulate employees to make changes in their job designs and how often this should take place.

\section{CONCLUSION}

With this theoretical paper we wish to contribute to the job redesign literature and, more generally, to the literature on positive organisational behaviour (Bakker \& Schaufeli, 2008). Instead of focusing on jobs when redesigning them, we argue that the focus should be on the individuals who perform the job. In this way, employees are more likely to be motivated and to experience well-being when performing the job because it better fits their individual abilities and needs. Organisations that regularly assess the person-job fit of their employees may, in turn, experience important benefits from these healthy, thriving and motivated employees who individually redesign their own jobs if necessary.

\section{REFERENCES}

Bakker, A.B., \& Demerouti, E. (2007). The job demands-resources model: State of the art. Journal of Managerial Psychology, 22, 309-328.

Bakker, A.B., Demerouti, E., \& Euwema, M.C.(2005). Job resources buffer the impact of job demands on burnout. Journal of Occupational Health Psychology, 10, 170-180.

Bakker, A.B., Demerouti, E., \& Schaufeli, W.B. (2003). Dual processes at work in a call centre: An application of the job demands-resources model. European Journal of Work and Organizational Psychology, 12, 393-417.

Bakker, A.B., Demerouti, E., \& Verbeke, W. (2004). Using the job demands-resources model to predict burnout and performance. Human Resource Management, 43, 83-104.

Bakker, A.B., Hakanen, J.J., Demerouti, E., \& Xanthopoulou, D. (2007). Job resources boost work engagement, particularly when job demands are high. Journal of Educational Psychology, 99, 274-284.

Bakker, A.B., \& Schaufeli, W.B. (2008). Positive organizational behavior: Engaged employees in flourishing organizations. Journal of Organizational Behavior, 29, 147-154.

Bandura, A. (1977). Self-efficacy: Toward a unifying theory of behavioural change. Psychological Review, 84, 191-215.

Bandura, A. (2001). Social cognitive theory: An agentic perspective. Annual Review of Psychology, 52, 1-26.

Bateman, T.S., \& Crant, M.J. (1993). The proactive component of organizational behavior: A measure and correlates summary. Journal of Organizational Behavior, 14, 103-119.

Berg, J.M., Dutton, J.E., \& Wrzesniewski, A. (2008). What is job crafting and why does it matter? Retrieved June 22, 2009, from http://www.bus.umich.edu/Positive/POS-Teachingand-Learning/ListPOS-Cases.htm
Biddle, B.J. (1979). Role theory: Expectations, identities, and behaviors. New York: Academic.

Cable, D.M., \& DeRue, D.S. (2002). The convergent and discriminant validity of subjective fit perceptions. Journal of Applied Psychology, 87, 875-884.

Cable, D.M., \& Judge, T.A. (1996). Person organization fit, job choice decisions, and organizational entry. Organizational Behavior and Human Decision Processes, 67, 294-311.

Cavanaugh, M.A., Boswell, W.R., Roehling, M.V., \& Boudreau, J.W. (2000). An empirical examination of self-reported work stress among U.S. managers. Journal of Applied Psychology, $85,65-74$.

Crant, J.M. (1995). The proactive personality scale and objective job performance among real estate agents. Journal of Applied Psychology, 80, 532-537.

Crant, J.M. (2000). Proactive behavior in organizations. Journal of Management, 26, 435-462.

Crowe, E., \& Higgins, T.E. (1997). Regulatory focus and strategic inclinations: Promotion and prevention in decision-making. Organizational Behavior and Human Decision Processes, 69 117-132.

Deci, E.L., \& Ryan, R.M. (2000). The 'what' and 'why' of goal pursuits: Human needs and the self-determination of behavior. Psychological Inquiry, 11, 227-268.

Demerouti, E., Bakker, A.B., Nachreiner, F., \& Schaufeli, W.B. (2001). The job demands-resources model of burnout. Journal of Applied Psychology, 86, 499-512.

Fay, D., \& Frese, M. (2001). The concept of personal initiative: An overview of validity studies. Human Performance, 14, 97-124.

Frese, M., \& Fay, D. (2001). Personal initiative: An active performance concept for work in the 21st century. Research in Organizational Behavior, 23, 133-187.

Frese, M., Garst, H., \& Fay, D. (2007). Making things happen: Reciprocal relationships between work characteristics and personal initiative in a four-wave longitudinal structural equation model. Journal of Applied Psychology, 92, 10841102

Frese, M., Fay, D., Hilburger, T., Leng, K., \& Tag, A. (1997). The concept of personal initiative: Operationalization, reliability and validity in two German samples. Journal of Occupational and Organizational Psychology, 70, 139-161.

Ghitulescu, B.E. (2006). Shaping tasks and relationships at work: Examining the antecedents and consequences of employee job crafting. Unpublished doctoral dissertation, University of Pittsburgh, Pittsburgh.

Grant, A.M., \& Ashford, S.J. (2008). The dynamics of proactivity at work. Research in Organizational Behavior, 28, 3-34.

Grant, A.M., \& Parker, S.K. (2009). Redesigning work design theories: The rise of relational and proactive perspectives. The Academy of Management Annals, 3, 317-375.

Hackman, J.R., \& Oldham, G.R. (1976). Motivation through the design of work: Test of a theory. Organizational Behavior and Human Performance, 16, 250-279.

Hakanen, J.J., Bakker, A.B., \& Demerouti, E. (2005). How dentists cope with their job demands and stay engaged: The moderating role of job resources. European Journal of Oral Sciences, 113, 479-487.

Higgins, E.T. (1998). Promotion and prevention: Regulatory focus as a motivational principle. Advances in Experimental Social Psychology, 30, 1-46.

Hobfoll, S.E. (1989). Conservation of resources: A new attempt at conceptualizing stress. American Psychologist, 44, 513524.

Hornung, S., Rousseau, D.M., \& Glaser, J. (2008). Creating flexible work arrangements through idiosyncratic deals. Journal of Applied Psychology, 93, 655-664.

Jackson, L., \& Rothmann, S. (2006). Occupational stress, organizational commitment, and ill-health of educators in the North West province. South African Journal of Education, $26,75-95$. 
Karasek, R.A., \& Theorell, T. (1990). Healthy work, stress, productivity, and the reconstruction of working life. New York: Basic Books.

Kiggundu, M.N. (1983). Task interdependence and job design: Test of a theory. Organizational Behavior and Human Performance, 31, 145-172.

Kristof-Brown, A.L., Zimmerman, R.D., \& Johnson, E.C. (2005). Consequences of individuals' fit at work: A meta-analysis of person-job, person-organization, person-group, and person-supervisor fit. Personnel Psychology, 58, 281-342.

Lai, L., Rousseau, D.M., \& Chang, K.T.T. (2009). Idiosyncratic deals: Coworkers as interested third parties. Journal of Applied Psychology, 94, 547-556.

Lauver, K.J., \& Kristof-Brown, A. (2001). Distinguishing between employees' perceptions of person-job and personorganization fit. Journal of Vocational Behavior, 59, 454-470.

LePine, J.A., \& Van Dyne, L. (1998). Predicting voice behavior in work groups. Journal of Applied Psychology, 83, 853-868.

LePine, J.A., Podsakoff, N.P., \& LePine, M.A. (2005). A metaanalytic test of the challenge stressor-hindrance stressor framework: An explanation for inconsistent relationships among stressors and performance. Academy of Management Journal, 48, 764-775.

Lewig, K.A., Xanthopoulou, D., Bakker, A.B., Dollard, M.F., \& Metzer, J.C. (2007). Burnout and connectedness among Australian volunteers: A test of the job demands-resources model. Journal of Vocational Behavior, 71, 429-445.

Lyons, P. (2008). The crafting of jobs and individual differences. Journal of Business Psychology, 23, 25-36.

Morrison, E.W., \& Phelps, C.C. (1999). Taking charge at work: Extrarole efforts to initiate workplace change. Academy of Management Journal, 42, 403-419.

Noar, S.M., Benac, C.N., \& Harris, M.S. (2007). Does tailoring matter? Meta-analytic review of tailored print health behavior change interventions. Psychological Bulletin, 133, 673-693.

Parker, S.K. (1998). Enhancing role breadth self-efficacy: The roles of job enrichment and other organizational interventions. Journal of Applied Psychology, 83, 835-852.

Parker, S.K., \& Ohly, S. (2008). Designing motivating jobs. In R. Kanfer, G. Chen \& R. Pritchard (Eds.), Work motivation: Past, present, and future. SIOP Organizational Frontiers Series. New York, NY: Psychology Press.

Parker, S.K., Williams, H.M., \& Turner, N. (2006). Modeling the antecedents of proactive behavior at work. Journal of Applied Psychology, 91, 636-652.

Peterson, U., Demerouti, E., Bergström, G., Ásberg, M., \& Nygren, A. (2008). Work characteristics and sickness absence in burnout and nonburnout groups: A study of Swedish health care workers. International Journal of Stress Management, 15, 153-172.

Petty, R.E., \& Cacioppo, J.T. (1986). Communication and persuasion: Central and peripheral routes to attitude change. New York: Springer/Verlag.

Richardsen, A.M., Burke, R.J., \& Martinussen, M. (2006). Work and health outcomes among police officers: The mediating role of police cynicism and engagement. International Journal of Stress Management, 13, 555-574.

Rugulies, R., Christensen, K.B., Borritz, M., Villadsen, E., Bültmann, U., \& Kristensen, T.S. (2007). The contribution of the psychosocial work environment to sickness absence in human service workers: Results of a 3-year follow-up study. Work E Stress, 21, 293-311.
Salanova, M., Agut, S., \& Peiró, J. M. (2005). Linking organizational resources and work engagement to employee performance and customer loyalty: The mediation of service climate. Journal of Applied Psychology, 90, 1217-1227.

Salanova, M., Bakker, A.B., \& Llorens, S. (2006). Flow at work: Evidence for a gain spiral of personal and organizational resources. Journal of Happiness Studies, 7, 1-22.

Salanova, M., Schaufeli, W.B., Xanthopoulou, D., \& Bakker, A.B. (2010). Gain spirals of resources and work engagement. In A.B. Bakker \& M.P. Leiter (Eds.), Work engagement: A handbook of essential theory and research. New York: Psychology Press.

Schein, E.H. (1971). Occupational socialization in the professions: The case of role innovation. Journal of Psychiatric Research, 8, 521-530.

Seibert, S.E., Kraimer, M.L., \& Crant, J.M. (2001). What do proactive people do? A longitudinal model linking proactive personality and career success. Personnel Psychology, 54, 845-874.

Skinner, C.S., Campbell, M.K., Rimer, B.K., Curry, S., \& Prochaska, J.O. (1999). How effective is tailored print communication? Annals of Behavioral Medicine, 21, 290-298.

Smeets, T.M.P.H., Kremers, S.P.J., De Vries, H., \& Brug, J. (2007). Effects of tailored feedback on multiple health behaviors. Annals of Behavioral Medicine, 33, 117-123.

Speier, C., \& Frese, M. (1997). Generalized self-efficacy as a mediator and moderator between control and complexity at work and personal initiative: A longitudinal field study in East Germany. Human Performance, 10, 171-192.

Staw, B.M., \& Boettger, R.D. (1990). Task revision: A neglected form of work performance. Academy of Management Journal, 33, 534-559.

Strümpfer, D.J.W. (1990). Salutogenesis: A new paradigm. South African Journal of Psychology, 20, 268-270.

Strümpfer, D.J.W. (2006). The strengths perspective: Fortigenesis in adult life. Social Indicators Research, 77, 11-36.

Vandelanotte, C., De Bourdeaudhuij, I., \& Brug, J. (2007). Twoyear follow-up of sequential and simultaneous interactive computer-tailored interventions for increasing physical activity and decreasing fat intake. Annals of Behavioral Medicine, 33, 213-219.

Van den Broeck, A., Vansteenkiste, M., De Witte, H., \& Lens, W. (2008). Explaining the relationships between job characteristics, burnout, and engagement: The role of basic psychological need satisfaction. Work E Stress, 22, 277-294.

Van Maanen, J., \& Schein, E.H. (1979). Toward a theory of organizational socialization. Research in Organizational Behavior, 1, 209-298.

Vough, H.C., \& Parker, S.K. (2008). Work design research: Still going strong. In J. Barling \& C.L. Cooper (Eds.) Handbook of Organizational Behavior: Micro Approaches. Sage Publications.

Wrzesniewski, A., \& Dutton, J.E. (2001). Crafting a job: Revisioning employees as active crafters of their work. Academy of Management Review, 26, 179-201.

Xanthopoulou, D., Bakker, A.B., Demerouti, E., \& Schaufeli, W.B. (2009). Work engagement and financial returns: A diary study on the role of job and personal resources. Journal of Occupational and Organizational Psychology, 82, 183-200. 